\title{
Structural, optical and fluorescence properties of wet chemically synthesized $\mathrm{ZnO}: \mathrm{Pd}^{2+}$ nanocrystals
}

\author{
Jasmeet Kaur ${ }^{1}$, Praveen Kumar ${ }^{2 *}$, Thangaiah Stephen Sathiaraj ${ }^{3}$ and Rengasamy Thangaraj ${ }^{1}$
}

\begin{abstract}
This paper presents the structural, optical and photoluminescence properties of wet chemically synthesized ZnO: $\mathrm{Pd}^{2+}$ colloidal nanocrystals characterised by $\mathrm{X}$-ray diffraction, scanning electron microscopy/energy-dispersive X-ray spectroscopy (EDS) and Fourier transform infrared spectroscopic techniques. Increase in lattice parameters from diffraction data indicates the incorporation of $\mathrm{Pd}^{2+}$ in the $\mathrm{ZnO}$ crystal lattice. A small amount of dopant favours the formation of stoichiometric $\mathrm{ZnO}$ nanoparticles; otherwise, non-stoichiometric nanocrystal formation was observed from the EDS data. The optical gap was found to decrease with the doping concentration, except for the small dopant level of $0.05 \%$ of $\mathrm{Pd}^{2+}$ where an increase in the optical gap was observed. Intensities of characteristic luminescence bands for pure $\mathrm{ZnO}$ nanocrystals $(357,387$ and $420 \mathrm{~nm}$ ) were found to decrease with the increasing $\mathrm{Pd}^{2+}$ concentration, and two new bands centred at 528 and $581 \mathrm{~nm}$ for $0.5 \% \mathrm{Pd}^{2+}$ concentration were observed. These results have been explained on the basis of change in the oxygen vacancy-related defects and/or formation of new trap states which in turn affect the luminescence properties of $\mathrm{ZnO}: \mathrm{Pd}^{2+}$ nanocrystals, which are important in the realisation of visible light-emitting solid-state devices.
\end{abstract}

Keywords: ZnO nanocrystals, Wet chemical method, XRD, FTIR, Optical and fluorescence spectroscopies

\section{Background}

Transition metal-doped metal oxide nanocrystals have attracted considerable interest in the scientific community due to their unique optical and electro-optical properties. Among them, zinc oxide $(\mathrm{ZnO})$ which has a wide bandgap $(3.37 \mathrm{eV})$ and high exciton binding energy $(60 \mathrm{meV})$ is a potential host material for doping transition metal ions [1]. Various theoretical and experimental studies on $\mathrm{ZnO}$ reveal a much wider scope in terms of nanocrystal shapes (wire, rod, cone and spherical), lattice structures, doping, surface modifications as well as synthesis conditions for tailoring the physical and optical properties of these nanocrystals [2-5]. Various dopants such as transition metals, $\mathrm{Mn}, \mathrm{Fe}, \mathrm{Co}$ and $\mathrm{Ni}$, and rare earth elements, $\mathrm{Eu}, \mathrm{Er}$ and $\mathrm{Tb}$, have successfully been incorporated into the colloidal semiconducting nanocrystals $(\mathrm{ZnO})$ for tailoring their characteristic

\footnotetext{
*Correspondence: prafiziks@gmail.com

${ }^{2}$ Nanotechnology Research Centre, DAV Institute of Engineering and

Technology, Jalandhar 144008, India

Full list of author information is available at the end of the article
}

properties [6]. The resulting material combinations have novel magnetic properties, enhanced optical absorption, better luminescence effects and improved sensing response, which make them suitable for gas sensor device applications [7]. $\mathrm{Pd}^{2+}$-doped $\mathrm{ZnO}$ shows good stability to a wide range of chemical compounds along with enhancement in sensitivity and response time [8-11]. CO gas sensing characteristics, such as sensitivity to low concentrations, selectivity and response and recovery times, were found to improve in $\mathrm{Pd}$-doped $\mathrm{ZnO}$ nanofibers synthesized by electrospinning method [11]. Recently, it was reported that decorating $\mathrm{ZnO}$ nanorod arrays with Pd nanoparticles enhances the gas sensing characteristics due to the acceleration in sensing reaction [12]. The enhancement in gas sensing activity with the addition of $\mathrm{Pd}(5$ at \%) for $\mathrm{ZnO}$ nanostructures has also been reported by Gondal et al. [13]. The significance of Pd-doped nanostructures can be understood properly by knowing the effect of composition on various structure/property relationships. Therefore, in view of the importance of $\mathrm{Pd}$ doping, we are reporting the 
structural, optical and fluorescent properties of colloidal $\mathrm{ZnO}: \mathrm{Pd}^{2+}$ nanocrystals synthesized by wet chemical precipitation technique.

\section{Methods}

Pd-doped $\mathrm{ZnO}$ nanocrystals were grown by wet chemical method based on alkaline-activated hydrolysis and condensation of zinc acetate in dimethyl sulfoxide (DMSO) to form $\mathrm{ZnO}$ nanocrystals [7]. Analytical grade reagents without any further purification were used in this study. A 2.5-mmol solution of tetramethyl ammonium hydroxide mixed in dry ethanol $(5 \mathrm{ml})$ was added dropwise to a solution of $0.1 \mathrm{M}$ zinc acetate solution in DMSO $(15 \mathrm{ml})$ under vigorous stirring at room temperature. The same method was also used for synthesizing the $\mathrm{Pd}$-doped $\mathrm{ZnO}$ by varying the palladium acetate concentration $(0.05,0.1,0.2$ and $0.5 \mathrm{~mol} \%)$ during the reaction. Synthesis with higher dopant concentrations resulted in a black residue with very little yield. Suspended nanocrystals were precipitated from DMSO by adding a non-solvent such as ethyl acetate $(40 \mathrm{ml})$, and the nanocrystals were re-suspended in dry ethanol. The process was repeated three times, and the aggregates of pure $\mathrm{ZnO}$ and $\mathrm{ZnO}: \mathrm{Pd}^{2+}$ nanocrystals were airdried to get the final powders. For surface passivation, the known quantity of powders was added to the molten trioctylphosphine oxide (TOPO), stirred at $150^{\circ} \mathrm{C}$ for 1.5 $\mathrm{h}$, then cooled, washed with ethanol and finally centrifuged repeatedly to remove the excess TOPO. The stabilised nanoparticles were finally suspended in toluene to form stable, high-optical-quality colloidal solutions for optical absorption and fluorescence studies.

The synthesized nanocrystals were characterised by Xray diffraction (XRD) (D8 Focus, BRUKER, Ettlingen, Germany) operated at $40 \mathrm{kV}$ and $20 \mathrm{~mA}$ using $\mathrm{Cu}-\mathrm{K}_{\alpha 1}$ radiation. Surface morphology and dopant concentrations were obtained by scanning electron microscopy/ energy-dispersive X-ray spectroscopy (SEM/EDS) (JEOL 6610 LV, JEOL Ltd., Akishima, Tokyo, Japan). Fourier transform infrared spectroscopy (FTIR) was used to study the molecular structure in the $\left(4,000\right.$ to $\left.400 \mathrm{~cm}^{-1}\right)$ spectral region using the $\mathrm{KBr}$ pallet method (660 Varian Resolution, Palo Alto, CA, USA). Absorption spectra of the colloidal solutions in quartz cuvettes with an optical path length of $1 \mathrm{~cm}$ were collected using a UV-vis spectrophotometer (Lambda 35, PerkinElmerInstruments, Branford, CT, USA). Photoluminescence emission spectra at $350 \mathrm{~nm}$ of excitation energy were recorded using a fluorescence spectrometer (Lambda 45, PerkinElmer Instruments).

\section{Results and discussion}

Figure 1 shows the XRD patterns for pure and $\mathrm{Pd}^{2+}$-doped $\mathrm{ZnO}$ nanocrystals. The observed strong diffraction peaks

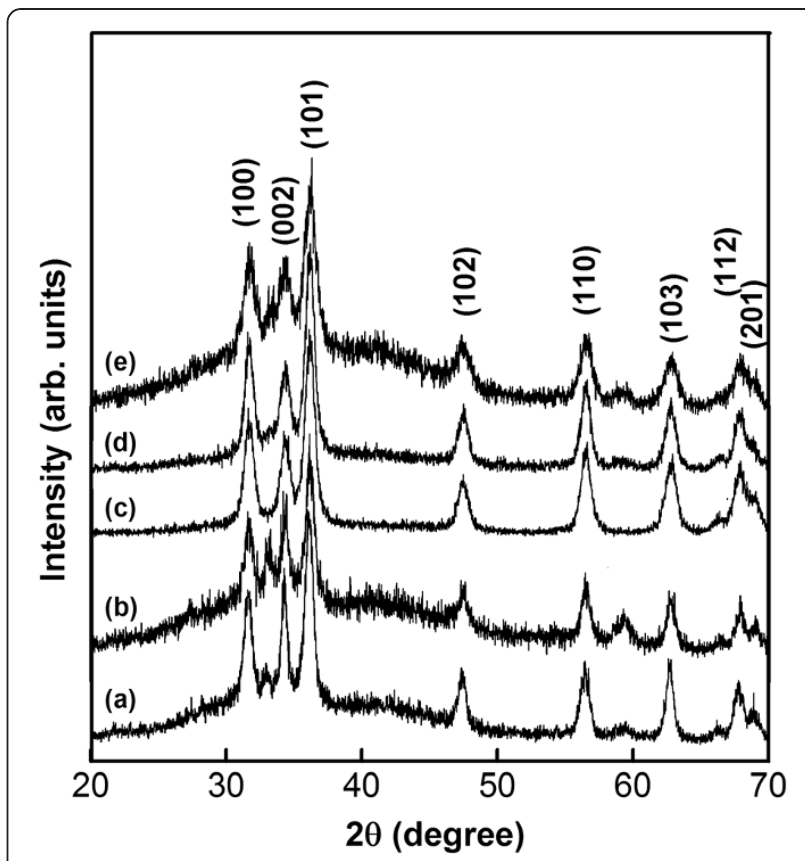

Figure 1 XRD patterns of $\mathrm{Pd}^{2+}$-doped $\mathrm{ZnO}$ nanoparticles. (a) $0.0 \%$, (b) $0.05 \%$, (c) $0.1 \%$, (d) $0.2 \%$ and (e) $0.5 \%$.

(100), (002), (101), (102), (110), (103), (201), (112) and (200) for all samples are consistent with the wurtzite $\mathrm{ZnO}$ phase (JPCDS 36-1451). The crystallite size, determined from X-ray line broadening using Debye Scherrer's formula, was found to be $10.5 \pm 1.5 \mathrm{~nm}$ for all samples. The broadening of the diffraction peaks indicates different crystal sizes which form different polycrystalline aggregates $[14,15]$. The crystallite size and strain depend on the $2 \theta$ peak position which enables us to determine the effect of peak broadening using the Williamson-Hall (W-H) method [16,17]:

$$
\beta \cos \theta=\frac{k \lambda}{D}+4 \varepsilon \sin \theta .
$$

The plot of $4 \sin \theta$ versus $\beta \cos \theta$ taking (100), (002), (101), (102), (110) and (103) lattice planes corresponding to the wurtzite phase of $\mathrm{ZnO}$ are shown in Figure 2. From the linear fit to the data, the crystallite size $D$ was extracted from the $y$-intercept and the strain $\varepsilon$ from the slope of the straight line. The strain is due to the incorporation of a dopant in the periodic lattice. The W-H plots show a negative strain for pure and $\mathrm{Pd}^{2+}$-doped $\mathrm{ZnO}$ nanoparticles which is an indication of lattice shrinkage [17].

The effect of this strain can be evaluated by calculating the lattice parameters such as the interplanar spacing $d$, the lattice constants $(a, b$ and $c$ ) and the unit cell volume 


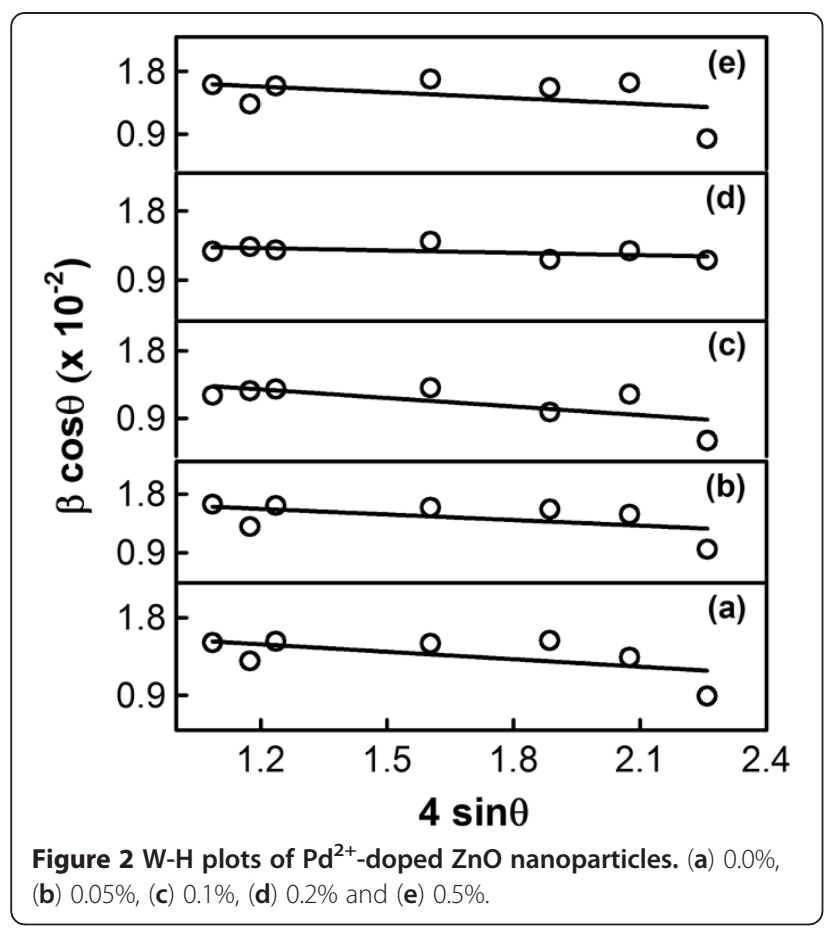

$V$ which were calculated from the lattice geometry equations as given below [17]:

$$
\begin{aligned}
& \lambda=2 d \sin \theta, \\
& \frac{1}{d^{2}}=\frac{4}{3}\left(\frac{h^{2}+h k+k^{2}}{a^{2}}\right)+\frac{l^{2}}{c^{2}}, \\
& V=\frac{\sqrt{3}}{3} a^{2} c=0.866 a^{2} c .
\end{aligned}
$$

The obtained lattice parameters along with particle size for different samples are summarised in Table 1. Similar values of the lattice parameters have been reported for the undoped $\mathrm{ZnO}$ nanoparticles [17]. It has been observed that the lattice parameters ( $a$ and $c$ ) increases with the increase in dopant concentration. Pd ions substitute for the isovalent $\mathrm{Zn}$ ions at the octahedral interstitial site as compared to the tetrahedral site without significant lattice distortion in the $\mathrm{ZnO}$ crystallites [18]. The variation in lattice dimension with $\mathrm{Pd}^{2+}$ content preliminarily implies that $\mathrm{Pd}^{2+}$ was substituted for $\mathrm{Zn}^{2+}$ in $\mathrm{ZnO}$; the detailed effect on optical properties will be discussed later in this paper.

The SEM images and EDS spectra for the assynthesized nanocrystals are shown in Figure 3, and the relative atomic compositions for each sample are summarised in Table 2. The $R$ values, i.e. the ratio of number of anions to cations $\left(\mathrm{O}^{2-} /(\mathrm{Zn}, \mathrm{Pd})^{2+}\right)$ for a given sample, are also tabulated. It is observed that for small dopant concentrations $\left(0.05 \% \mathrm{Pd}^{2+}\right)$, the samples were near stoichiometric.

Figure 4 shows the FTIR spectra of pure and doped $\mathrm{ZnO}: \mathrm{Pd}^{2+}$ nanocrystals. The peak at 3,370 $\pm 20 \mathrm{~cm}^{-1}$ can be assigned to $\mathrm{O}-\mathrm{H}$ stretching mode for the adsorbed atmospheric moisture, and at about $1,500 \mathrm{~cm}^{-1}$, the $\mathrm{C}=\mathrm{O}$ stretching mode arises from the absorption of atmospheric $\mathrm{CO}_{2}$ on the surface of the nanoparticles [19]. The main absorption band at $441.2 \mathrm{~cm}^{-1}$ is due to $\mathrm{Zn}-\mathrm{O}$ stretching vibrations with a shift in their position as 460.0, $440.8,437.6,444.1$ and $452.6 \mathrm{~cm}^{-1}$ for $0.05 \%, 0.1 \%, 0.2 \%$ and $0.5 \% \mathrm{Pd}^{2+}$-doped $\mathrm{ZnO}$ nanocrystals, respectively. The change in the peak position of $\mathrm{ZnO}$ absorption band reflects that the $\mathrm{Zn}-\mathrm{O}-\mathrm{Zn}$ network is perturbed by the presence of $\mathrm{Pd}^{2+}$ in its environment $[20,21]$. Therefore, the FTIR results also indicate that Pd is occupying the $\mathrm{Zn}$ position in the $\mathrm{ZnO}$ matrix as observed in XRD measurements.

Figure 5 shows the optical absorption spectra for TOPOcapped $\mathrm{ZnO}: \mathrm{Pd}^{2+}$ nanocrystals at room temperature. The two prominent excitonic absorption peaks at 303 and 363 $\mathrm{nm}$ for $\mathrm{ZnO}$ nanoparticles were blue-shifted as compared with the bulk exciton absorption peak of $\mathrm{ZnO}(373 \mathrm{~nm})$ which is due to the quantum size effects in nanocrystals $[21,22]$. The variation of $(\alpha h v)^{2}$ versus photon energy $(h v)$ for the synthesized nanocrystals is plotted in Figure 6. The optical gap $\left(E_{\mathrm{g}}\right)$ is estimated from the intercept of the extrapolated linear portion of the curve, and the values are summarised in Table 1. The value of optical gap increases to $3.23 \mathrm{eV}(0.05 \% \mathrm{Pd})$ from $3.17 \mathrm{eV}$ (for pure $\mathrm{ZnO}$ nanocrystals) and then decreases to $2.96 \mathrm{eV}$ for $0.5 \%$ of Pd dopant. The structural modifications along with the improved crystallinity give rise to an increase in the Tauc's slopes or decrease the tailing; hence, there is an increase in the optical gap for a small amount of dopant in $\mathrm{ZnO}$ nanocrystals [23]. The small dopant also improves stoichiometry (i.e.

Table 1 Particle size, lattice parameters, volume, $D_{\mathrm{W}-\mathrm{H}}, \varepsilon$ and $E_{\mathrm{o}}$ for pure and doped ZnO:Pd ${ }^{2+}$ nanocrystals

\begin{tabular}{lccllcrc}
\hline $\boldsymbol{x}$ (at.\%) & $\boldsymbol{D}_{\mathbf{S}}$ & $\boldsymbol{a}(\mathbf{n m})$ & $\boldsymbol{c}(\mathbf{n m})$ & $\boldsymbol{V}\left(\mathbf{n m}^{\mathbf{3}}\right)$ & $\boldsymbol{D}_{\mathbf{W - H}}(\mathbf{n m})$ & $\boldsymbol{\varepsilon} \times \mathbf{1 0}^{-\mathbf{3}}$ & $\boldsymbol{E}_{\mathbf{o}}(\mathrm{eV})$ \\
\hline 0.00 & 9.60 & 0.3255 & 0.5238 & 0.04806 & 7.9 & 2.87 & 3.17 \\
\hline 0.05 & 8.82 & 0.3256 & 0.5239 & 0.04809 & 8.3 & 3.23 \\
\hline 0.10 & 12.00 & 0.3257 & 0.5241 & 0.04817 & 10.0 & 3.80 & 1.02 \\
\hline 0.20 & 11.37 & 0.3258 & 0.5242 & 0.04821 & 7.5 & 2.14 \\
\hline 0.50 & 9.00 & 0.3259 & 0.5244 & 0.04826 & 2.78 \\
\hline
\end{tabular}

The particle size $\left(D_{\mathrm{S}}\right)$, lattice parameters $(a$ and $c)$, volume $(V), \mathrm{W}-\mathrm{H}$ particle size $\left(D_{\mathrm{W}-\mathrm{H}}\right)$, strain $(\varepsilon)$ and optical gap $\left(E_{\mathrm{o}}\right)$ for pure and doped $\mathrm{ZnO}: \mathrm{Pd}^{2+}$ nanocrystals. 

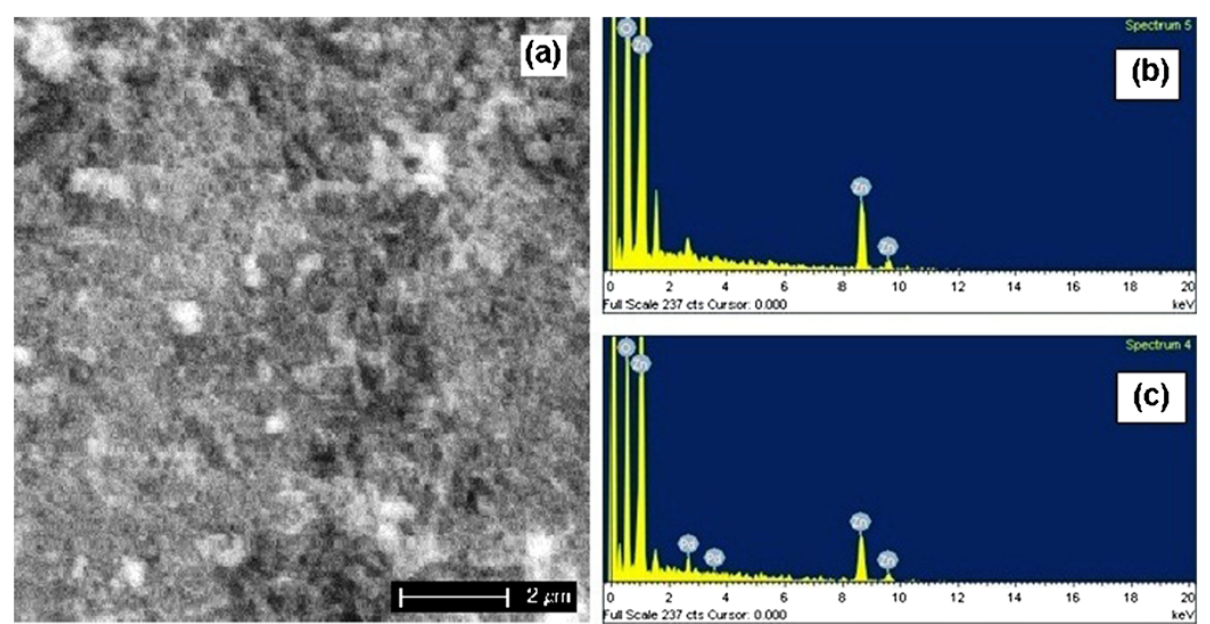

Figure 3 SEM image and EDS spectra. (a) The SEM image for 0.1 mol\% Pd ${ }^{2+}$-doped ZnO nanocrystals and the EDS spectra of (b) pure and (c) 0.1 mol\% $\mathrm{Pd}^{2+}$-doped $\mathrm{ZnO}$ nanocrystals.

$R=1$ for $0.05 \% \mathrm{Pd}^{2+}$ ), and further addition of dopant causes a deviation in stoichiometry due to the formation of oxygen vacancies in the synthesized nanocrystals. Thus, the red shift in the optical absorption edge can be explained on the basis of the increase in the defect density due to the formation of oxygen vacancies in doped $\mathrm{ZnO}$ nanoparticles and/or due to the effects of crystal-field splitting of $3 d$ energy levels on the electronic transitions involving $\mathrm{Pd}^{2+}$ ions substituting the $\mathrm{Zn}^{2+}$ lattice sites.

The fluorescence spectroscopy was generally used to elucidate the nature of traps/vacancies formed with the incorporation of dopants. The type of vacancies formed depends upon the synthesis conditions and techniques used [24]. The room temperature luminescence spectra for colloidal solution of $\mathrm{ZnO}: \mathrm{Pd}^{2+}$ nanocrystals at 350 $\mathrm{nm}$ of excitation energy are shown in Figure 7. Four luminescence peaks centred at 382, 413, 436 and $465 \mathrm{~nm}$ have been observed for the TOPO-capped $\mathrm{ZnO}$ nanocrystals. Generally, three emission bands are observed for $\mathrm{ZnO}$ nanocrystals [25]. The first band centred at 357 $\mathrm{nm}$ indicates band-to-band transition, the second band at $387 \mathrm{~nm}$ is for the radiative recombination of an electron and a hole, i.e. the excitonic emission [26] and the third emission at $420 \mathrm{~nm}$ may be attributed to the

\begin{tabular}{|c|c|c|c|c|c|}
\hline \multirow[t]{2}{*}{ Elements } & \multicolumn{5}{|c|}{$\mathrm{Pd}^{2+}$ content (mol\%) } \\
\hline & 0 & 0.05 & 0.10 & 0.20 & 0.50 \\
\hline Zn & 50.06 & 48.76 & 48.58 & 47.46 & 46.69 \\
\hline $\mathrm{Pd}$ & - & 1.24 & 1.52 & 2.66 & 3.49 \\
\hline $\mathrm{O}$ & 49.94 & 50.0 & 49.90 & 49.88 & 49.85 \\
\hline$R$ value & 99.8 & 100.0 & 99.6 & 99.5 & 99.3 \\
\hline
\end{tabular}

interstitial oxygen [25]. The luminescence at $435 \mathrm{~nm}$ may be due to the formation of $\mathrm{Zn}$ interstitial defect [27]. A blue luminescence at $465 \mathrm{~nm}$ which is normally not observed for $\mathrm{ZnO}$ nanocrystals may be due to impurities introduced during the course of preparation and can be attributed to the intrinsic defects such as $\mathrm{O}$ or $\mathrm{Zn}$ vacancies to valence band transition [28].

The incorporation of dopant significantly affects the shape and position of the luminescence spectrum with the formation of new bands at 528 and $581 \mathrm{~nm}$ for $0.05 \%$ Pd contents. This visible luminescence can either

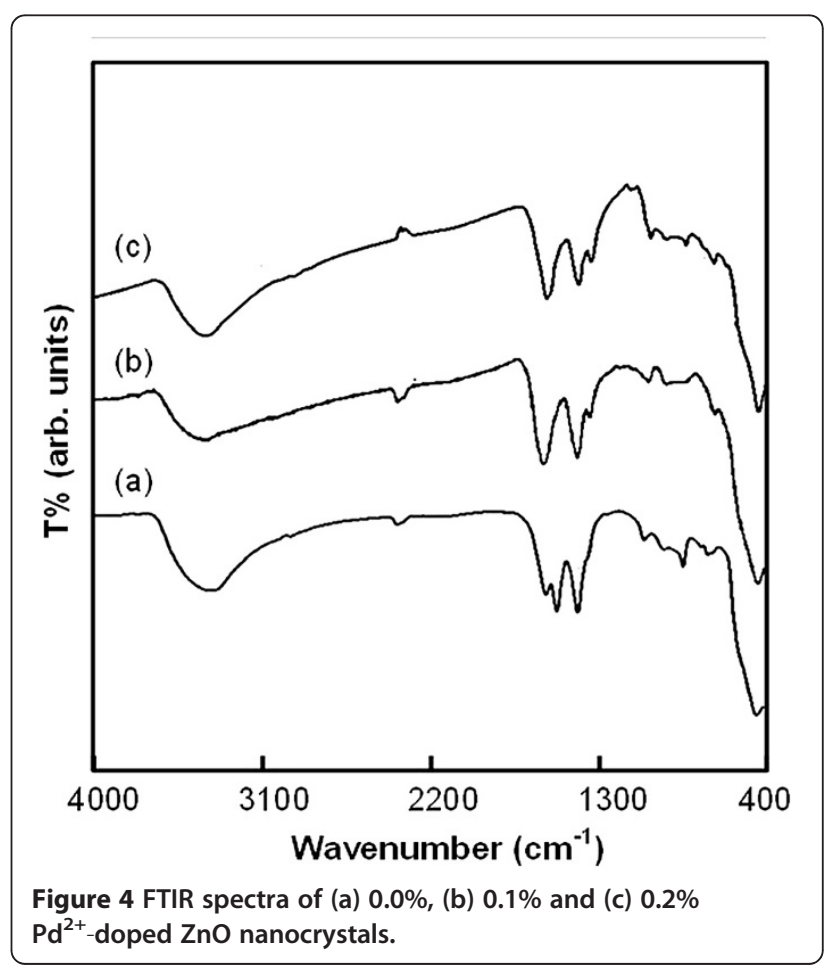



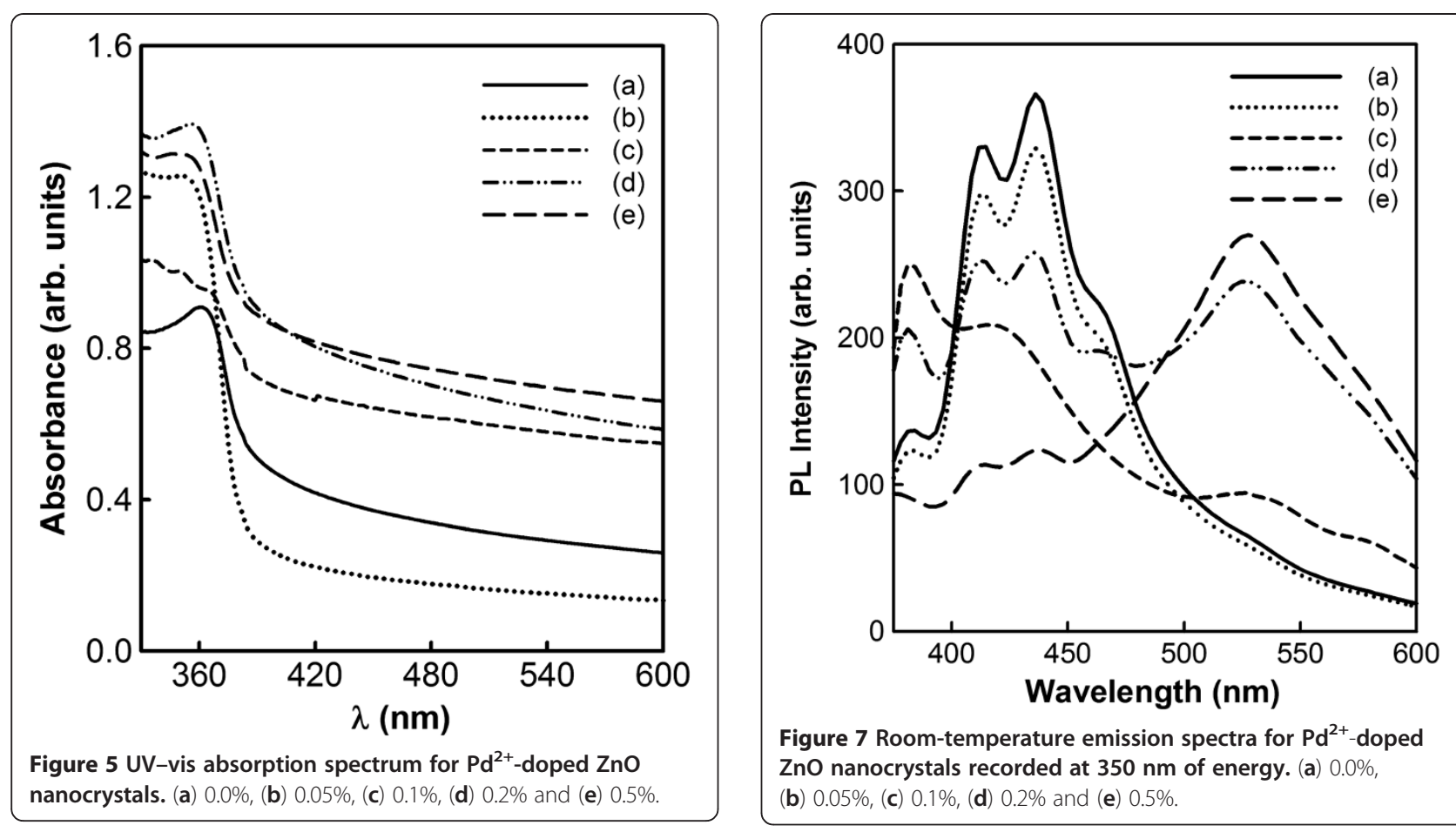

Figure 7 Room-temperature emission spectra for $\mathrm{Pd}^{2+}$-doped $\mathrm{ZnO}$ nanocrystals recorded at $350 \mathrm{~nm}$ of energy. (a) $0.0 \%$, (b) $0.05 \%$, (c) $0.1 \%$, (d) $0.2 \%$ and (e) $0.5 \%$.
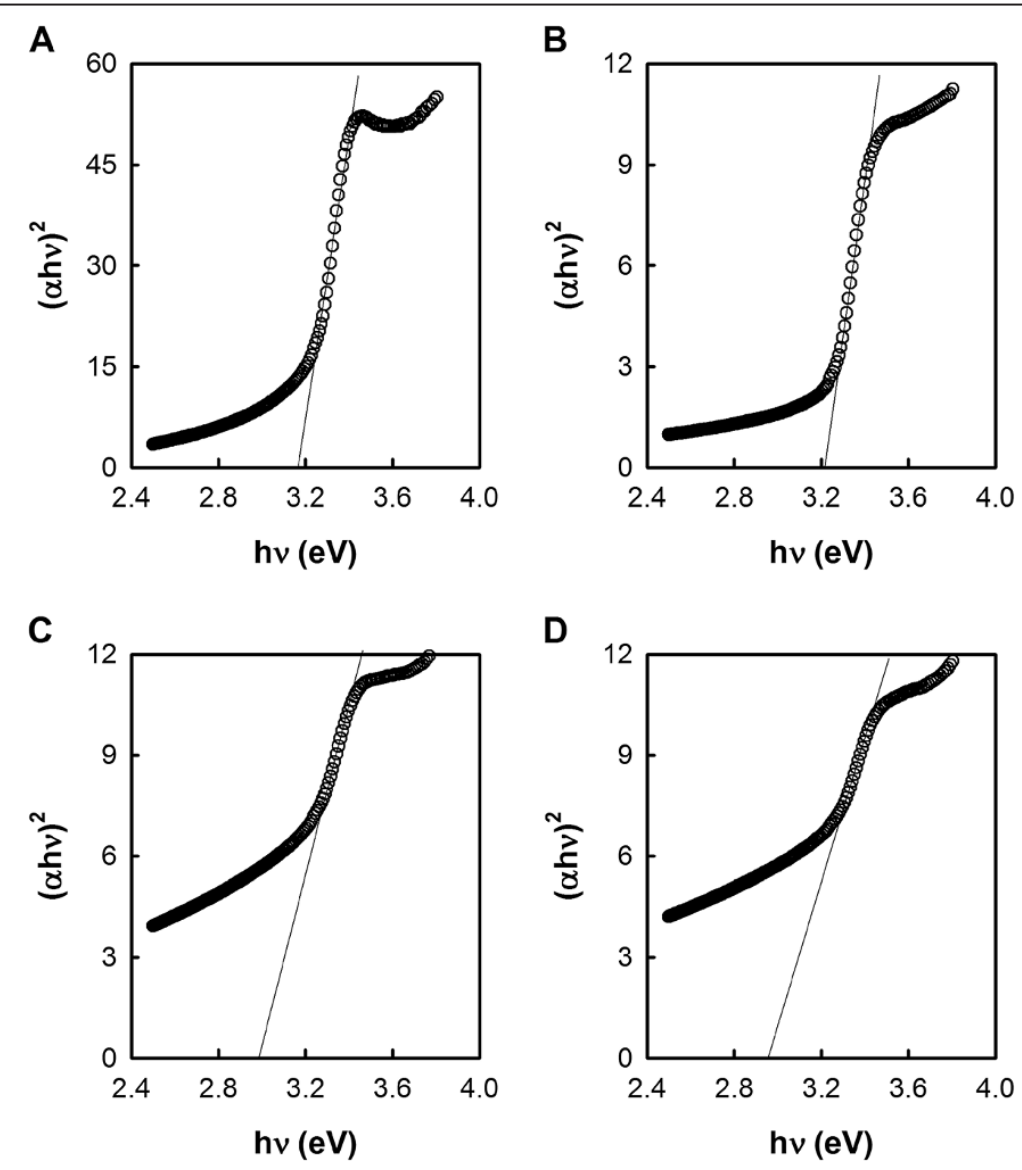

Figure 6 Plots of $(\boldsymbol{a h v})^{2}$ versus photon energy (hv) for $\mathbf{P d}^{2+}$-doped colloidal ZnO nanocrystals. (A) $0.0 \%$, (B) $0.05 \%$, (C) $0.2 \%$ and (D) $0.5 \%$. 
be ascribed to the formation of intrinsic oxygen vacancy defect states $\left(\mathrm{Vo}^{0}, \mathrm{Vo}^{+}\right.$and $\left.\mathrm{Vo}^{2+}\right)$ or $\mathrm{Zn}$ interstitials for $\mathrm{ZnO}$ nanocrystals [29]. The oxygen vacancies are located below the bottom of the conduction band $(\mathrm{CB})$ as $\mathrm{Vo}^{0}$, $\mathrm{Vo}^{+}$and $\mathrm{Vo}^{2+}$, from top to bottom. Thus, the green emission around $528 \mathrm{~nm}$ may be due to the recombination of a photogenerated hole with the singly ionised charged state of the specific defect [30,31]. On the other hand, the shallow accepter levels at $0.3 \mathrm{eV}$ above the top of the valence band are due to the zinc vacancy, and donor levels at $0.5 \mathrm{eV}$ below the bottom of the $\mathrm{CB}$ are due to $\mathrm{Zn}$ interstitials which have been reported from the first principle calculations [30]. As the $\mathrm{Pd}^{2+}$ concentration increases, the intensity of the green emission also increases, indicating an enhancement in the singly ionised oxygen vacancy $\left(\mathrm{Vo}^{+}\right)$in doped $\mathrm{ZnO}$ nanocrystals. The detailed mechanism for defect-mediated green emission for $\mathrm{ZnO}$ nanoparticles has been discussed elsewhere [32]. Similarly, the luminescence band at approximately $581 \mathrm{~nm}$ can be due to the dominance of other intrinsic defects or the incorporation of $\mathrm{Pd}^{2+}$ into the $\mathrm{ZnO}$ lattice which perturbs its band structure to form a discrete energy level within the bandgap. Therefore, it seems that the dopant incorporation controls the various aspects of the recombination process and favours the radiative transitions from the oxygen vacancies/trap levels in the bandgap to give a broad visible luminescence for the $\mathrm{Pd}^{2+}$-doped $\mathrm{ZnO}$ nanocrystals.

\section{Conclusions}

The alkaline-activated wet chemical method has been successfully utilised for the synthesis of colloidal $\mathrm{ZnO}: \mathrm{Pd}^{2+}$ nanocrystals at room temperature. It has been found that the dopant $\mathrm{Pd}^{2+}$ ions substitute for the $\mathrm{Zn}$ ions, without changing their wurtzite structure of the nanocrystals. The lattice parameters for the wurtzite phase of $\mathrm{ZnO}$ increase with the increase in dopant levels as 1.24 to 3.49 at.\% of $\mathrm{Pd}$. The optical gap initially increases with small doping $\left(0.05 \%\right.$ of $\left.\mathrm{Pd}^{2+}\right)$ and decreases with further addition of $\mathrm{Pd}^{2+}$ thereafter. Three characteristic luminescence bands at 357, 387 and $420 \mathrm{~nm}$ were observed for pure $\mathrm{ZnO}$ nanocrystals. New dominant bands centred at 528 and $581 \mathrm{~nm}$ for $0.5 \%$ of $\mathrm{Pd}^{2+}$-doped $\mathrm{ZnO}$ nanocrystals were observed. These results were attributed to the change in oxygen vacancyrelated defects and/or formation of new trap states which effectively controls the luminescence properties of the doped nanocrystals which is an effective technique for modulating their optical properties.

\section{Competing interests}

The authors declare that they have no competing interests.

\section{Authors' contributions}

JK perform the synthesis and took the necessary experimental data while PK supervised and prepared the manuscript. RT conducted the progress of the study and discussed the results in detail, and TSS performed the characterizations for the synthesized nanopowders. All authors read and approved the final manuscript.

\section{Authors' information}

JK has completed her B.Sc. (NM), M.Sc. (Applied Physics) and M. Phil. (Physics) from the GND University, Amritsar, India. She is presently working for her Ph. D. in Physics (Material Science) at the same university. PK is working as an assistant professor in the Nanotechnology Research Centre, DAV Institute of Engineering and Technology, Kabir Nagar, Jalandhar, India. He received his B. Sc. (NM) from the Himachal Pradesh University, Shimla, India and his M.Sc. (Applied Physics) from the GND University, Amritsar, India. He also got postdoctoral fellowships as SRF (extended) and as research associate from CSIR New Delhi for 3 years. He obtained his Ph.D. in the field of material science, some thermal, optical and structural characterization of chalcogenide semiconductors from the same institute. He has published more than 25 international journal publications to his credit. His current research interest includes synthesis and characterization of metal oxide semiconductors, polymer nanocomposites, chalcogenide thin films etc. TSS has completed his Ph.D. in Physics from Indian Institute of Technology Delhi, New Delhi, India and is presently working as associate professor (Physics) at the University of Botswana, Gaborone, Botswana. His main Research interests are

chalcogenide glasses, determination of optical constants of thin films, optical, electrical and structural properties of transparent conducting oxides, solar Energy materials, solar selective coatings, dye-sensitized solar cells and advanced material characterisation techniques. RT has completed his M.Sc. (Physics) from the Mysore University, Mysore, India and his Ph.D. (Physics) from the Indian Institute of Technology Delhi, New Delhi, India. He has also completed his post doctorate and worked as senior scientific officer at the Physics Department of the IIT Delhi, India. He has actively engaged in teaching/research with PG, Ph.D. and post doctorate students at the GND University, Amritsar, India. He has published more than 100 publications in reputable international journals. He has completed various research projects from the UGC, CSIR, DST etc. and is presently working as Emeritus professor (Physics) at the GND University, Amritsar, India.

\section{Acknowledgements}

Jasmeet Kaur is thankful to the head of the department for providing the necessary experimental facilities required to complete his M. Phil. dissertation work.

\section{Author details}

'Semiconductors Laboratory, Department of Physics, GND University, Amritsar 143005, India. ${ }^{2}$ Nanotechnology Research Centre, DAV Institute of Engineering and Technology, Jalandhar 144008 , India. ${ }^{3}$ Department of Physics, University of Botswana, Gaborone, Botswana.

Received: 20 August 2012 Accepted: 3 January 2013

Published: 16 January 2013

\section{References}

1. Ozgur, U, Alivov, YI, Liu, C, Take, A, Reshchikov, MA, Dogan, S, Avrutin, V, Cho, SJ, Markoc, H: A comprehensive review of ZnO materials and devices. J. Appl. Phys. 98, 041301 (2005)

2. Joo, J, Kwon, SG, Yu, JH, Hyeon, T: Synthesis of $\mathrm{ZnO}$ nanocrystals with cone, hexagonal cone, and rod shapes via non-hydrolytic ester elimination solgel reactions. Adv. Mater. 17(15), 1873 (2005)

3. Qu, F, Santos Jr, DR, Dantas, NO, Monte, AFG, Morais, PC: Effects of nanocrystal shape on the physical properties of colloidal $\mathrm{ZnO}$ quantum dots. Physica E 23, 410 (2004)

4. Kohls, M, Schmidt, T, Katschorek, H, Spanhel, L, Muller, G, Mais, N, Wolf, A, Forchel, A: A simple colloidal route to planar micropatterned Er@ZnO amplifiers. Adv. Mater. 11(4), 288 (1999)

5. Tong, YH, Liu, YC, Lu, SX, Dong, L, Chen, SJ, Xiao, ZY: The optical properties of ZnO nanoparticles capped with polyvinyl butyral. J. Sol-Gel Sci. Tech. 30, 157 (2004)

6. Ohno, H, Munekata, H, Penney, T, Molnar, SV, Chang, LL: Magnetotransport properties of p-type (In, Mn)As diluted magnetic III-V semiconductors. Phys. Rev. Lett. 68, 2664 (1992)

7. Schwartz, DA, Norberg, NS, Nguyen, QP, Parker, JM, Gamelin, DR: Magnetic quantum dots: synthesis, spectroscopy, and magnetism of $\mathrm{CO}^{2+}$ - and $\mathrm{Ni}^{2+}$ -Doped ZnO Nanocrystals. J. Am. Chem. Soc. 125, 13205 (2003) 
8. Wang, $\mathrm{X}$, Zhang, J, Zhu, Z, Zhu, J: Effect of $\mathrm{Pd}^{2+}$ doping on $\mathrm{ZnO}$ nanotetrapods ammonia sensor. Coll. Surf. A 276, 59 (2006)

9. Wang, X, Zhang, J, Zhu, Z, Zhu, J: Humidity sensing properties of $\mathrm{Pd}^{2+}$-doped ZnO nanotetrapods. Appl. Surf. Sci. 253, 3168 (2007)

10. Al-Zaidi, QG, Suhail, AM, Al-azawi, WR: Palladium-doped ZnO thin film hydrogen gas sensor. Appl. Phys. Res. 3(1), 89 (2011)

11. Wei, $\mathrm{S}, \mathrm{Yu}, \mathrm{Y}, \mathrm{Zhou}, \mathrm{M}$ : CO gas sensing of Pd-doped $\mathrm{ZnO}$ nanofibers synthesized by electrospinning method. Mater. Lett. 64(21), 2284 (2010)

12. Chang, CM, Hon, $\mathrm{MH}$, Leu, IC: Improvement in $\mathrm{CO}$ sensing characteristics by decorating $\mathrm{ZnO}$ nanorod arrays with $\mathrm{Pd}$ nanoparticles and the related mechanisms. RSC Adv. 2, 2469 (2012)

13. Gondal, MA, Alzahrani, AJ, Randhawa, MA, Siddiqui, MN: Morphology and antifungal effect of nano-ZnO and nano-Pd-doped nano-ZnO against Aspergillus and Candida. J. Environ. Sci. Health A 47, 1413 (2012)

14. Ramakanth, K: Basic of Diffraction and its Application. I.K. International Publishing House, New Delhi (2007)

15. Zhang, J, Zhang, $Y, X$ u, KW, Ji, V: General compliance transformation relation and applications for anisotropic hexagonal metals. Sol. Stat. Commun. $139,87(2006)$

16. Cullity, BD, Stock, SR: Elements of X-ray Diffraction. Prentice Hall Publication, New Delhi (2001)

17. Zak, AK, Majid, WHA, Abrishami, ME, Yousefi, R: X-ray analysis of ZnO nanoparticles by Williamson-Hall and size-strain plot methods. Sol. Stat. Sci. 13, 251 (2011)

18. Assadi, MHN, Zhang, Y, Zheng, RK, Ringer, SP, Li, S: Structural and electronic properties of Eu- and Pd-doped ZnO. Nano. Res. Lett. 6, 357 (2011)

19. Gondal, $\mathrm{MA}$, Drmosh, QA, Yamani, ZH, Saleh, TA: Synthesis of $\mathrm{ZnO}_{2}$ nanoparticles by laser ablation in liquid and their annealing transformation into ZnO nanoparticles. Appl. Surf. Sci. 256, 298 (2009)

20. Ahmed, F, Kumar, S, Arshi, N, Anwar, MS, Koo, BH, Lee, CG: Doping effects of $\mathrm{Co}^{2+}$ ions on structural and magnetic properties of $\mathrm{ZnO}$ nanoparticles. Microelect. Engg. 89, 129 (2011)

21. Dole, BN, Mote, VD, Huse, VR, Purushotham, Y, Lande, MK, Jadhav, KM, Shah, SS: Structural studies of $\mathrm{Mn}$ doped $\mathrm{ZnO}$ nanoparticles. Curr. Appl. Phys. 11, 762 (2011)

22. Sridevi, D, Rajendran, KV: Synthesis and optical characteristics of ZnO nanocrystals. Bull. Mater. Sci. 32, 165-168 (2009)

23. Kumar, $P$, Thangaraj, R, Sathiaraj, TS: Electrical and optical study of phase transitions in thermally evaporated GeTe films. Phys. Stat. Solidi A 208(4), 838 (2011)

24. Lakowicz, JR: Principles of Fluorescence Spectroscopy, 4th printing. Springer Science, Heidelberg (2006)

25. Modak, S, Acharya, S, Bandyopadhyay, A, Karan, S, Roy, SK, Chakrabarti, PK: Microstructural investigations and paramagnetic susceptibilities of zinc oxide, europium oxide and their nanocomposites. J. Mag. Mag. Mater. 322, 283 (2010)

26. Zhou, J, Zhao, F, Wang, Y, Zhang, Y, Yang, L: Size-controlled synthesis of ZnO nanoparticles and their photoluminescence properties. J. Lumin. 122, 195 (2007)

27. Goswami, N, Sharma, DK: Structural and optical properties of unannealed and annealed $\mathrm{ZnO}$ nanoparticles prepared by a chemical precipitation technique. Physica E 42, 1675 (2010)

28. Pereira, AS, Peres, M, Soares, MJ, Alves, E, Neves, A, Monteiro, T, Trindade, T: Synthesis, surface modification and optical properties of $\mathrm{Tb}^{3+}$-doped $\mathrm{ZnO}$ nanocrystals. Nanotechnology 17, 834 (2006)

29. Vanheusden, K, Seager, CH, Warren, WL, Tallant, DR, Voigt, JA: Correlation between photoluminescence and oxygen vacancies in $\mathrm{ZnO}$ phosphors. Appl. Phys. Lett. 68, 403 (1996)

30. Zhang, SB, Wei, SH, Zunger, A: Intrinsic n-type versus $p$-type doping asymmetry and the defect physics of ZnO. Phys. Rev. B. 63, 075205 (2001)

31. Yang, CL, Wang, JN, Ge, WK, Guo, L, Yang, SH, Shen, DZ, Wang, X, Zhang, J, Zhu, Z, Zhu, J: Enhanced ultraviolet emission and optical properties in polyvinyl pyrrolidone surface modified $\mathrm{ZnO}$ quantum dots. J. Appl. Phys. 90, 4489 (2001)

32. Sharma, PK, Dutta, RK, Pandey, AC: Alteration of magnetic and optical properties of ultrafine dilute magnetic semiconductor $\mathrm{ZnO}: \mathrm{Co}^{2+}$ nanoparticles. J. Coll. Inter. Sci. 345, 149 (2010)

doi:10.1186/2228-5326-3-4

Cite this article as: Kaur et al:: Structural, optical and fluorescence properties of wet chemically synthesized $\mathrm{ZnO}: \mathrm{Pd}^{2+}$ nanocrystals. International Nano Letters 2013 3:4.

\section{Submit your manuscript to a SpringerOpen ${ }^{\odot}$ journal and benefit from:}

- Convenient online submission

$\checkmark$ Rigorous peer review

- Immediate publication on acceptance

- Open access: articles freely available online

- High visibility within the field

- Retaining the copyright to your article

Submit your next manuscript at $>$ springeropen.com 